\title{
Employees' Perceptions of the Implementation of Robotics, Artificial Intelligence, and Automation (RAIA) on Job Satisfaction, Job Security, and Employability
}

\author{
Amisha Bhargava ${ }^{1}$ (D) $\cdot$ Marais Bester ${ }^{1} \cdot$ Lucy Bolton $^{1}$ \\ Received: 9 April 2020 / Revised: 15 July 2020 / Accepted: 27 July 2020 / Published online: 12 August 2020 \\ (C) The Author(s) 2020
}

\begin{abstract}
The study aimed at qualitatively exploring working adult's perceptions of the implementation of robotics, artificial intelligence (AI), and automation (RAIA) on their job security, job satisfaction, and employability. By means of a cross-sectional and exploratory design, the researchers conducted 21 semi-structured interviews with a diverse sample. The heterogeneous sample came from numerous industries for instance consulting, accounting and finance, and hospitality and varied seniority levels. The thematic analysis led to the emergence of five high-level themes and several sub-themes. The findings indicate that (a) "human touch" and "soft skills" remain irreplaceable and cannot be replicated by RAIA, (b) employees need to perceive RAIA as an opportunity and not a threat, (c) employees might experience a job satisfaction dilemma, and (d) organizations have to be well prepared pre- and post-industrial change. The findings could be used by industrial and organizational psychologists, human resource practitioners, and strategic information technology decision-makers when managing RAIA-related technological changes in organizations. Employees' suggestions and perceptions could be considered to mitigate the consequences of technological changes in organizations. Both employees and employers need to change their perspective toward RAIA technology, work with a flexible, open mind, and embrace the potential impact of RAIA advancements on job roles and responsibilities. Employees will have to follow a path of continuous learning and keep up with technology.
\end{abstract}

Keywords Robotics · Automation · Artificial intelligence · Job satisfaction · Job security · Employability · Organizational psychology $\cdot$ RAIA

\section{Introduction}

"Technology eliminates jobs, not work" (Bowen 1966, p. 9). Not every business leader thinks this way; perceptions of the potential for artificial intelligence (AI), robotics, the internet of things, automation, and technology to eliminate traditional jobs or create new ones vary from industry to industry (for review, see Ivanov 2017). Technology is believed to affect several jobs and render positions outmoded, as computers are becoming smarter, more creative, and more sophisticated (for review, see West 2015). With the increasing need for low costs, fast

Electronic supplementary material The online version of this article (https://doi.org/10.1007/s41347-020-00153-8) contains supplementary material, which is available to authorized users.

Amisha Bhargava

amish.1711@gmail.com

1 Heriot Watt University, Dubai, United Arab Emirates production, and consistency in the quality of products and supply chains, companies are becoming more dependent on robotics, artificial intelligence, and automation (RAIA) technologies (for review, see Webster and Ivanov 2019).

The implementation of RAIA started in the manufacturing industries and later expanded to various sectors of society and the economy (Webster and Ivanov 2019). Currently, the pool of employees that are less fearful of RAIA technologies in the workplace includes managers, professionals, and highly educated individuals in comparison with manual, less educated, white-collar employees. However, researchers predict that RAIA will have an impact on most roles in the future (Dekker et al. 2017).

Many researchers are concerned that RAIA may become so advanced that it will not only replace human employees but also become so complex that no human mind will be able to control it (Fast and Horvitz 2017). For example, Castelvecchi (2016) suggests that back in the 1990s, AI was considered a black box which could not be fully understood. Humans and AI will have to work hand in hand, which highlights the need 
to recruit employees with skills that complement the technologies (Plastino and Purdy 2018). This may be of concern to employees with regard to the impact of RAIA on their job security, job satisfaction, and employability and that of employers with regard to recruiting, retaining, and managing their workforce. To date, most studies that have explored the impact that RAIA technology has on the workforce have been quantitative in nature and do not capture the unique opinions of end-users (Chui et al. 2015; Kolbjørnsrud et al. 2016; McClure 2018). At the time of this study, a gap was evident in the qualitative research exploring the individuals' perceptions of their job security, job satisfaction, and employability within the context of RAIA and its potential impact on current, future jobs. This study aims to address this gap in the research.

\section{Impact of RAIA}

Research by Chui et al. (2015) suggests that automation is more likely to occur in activities rather than in occupations. RAIA technology can easily match or surpass human performance standards; it will not be limited to low-skilled, lowwage roles like home health aides and maintenance workers, but extended to executive or managerial tasks such as data and report analysis or preparing staff assignments (Chui et al. 2015; West 2015). RAIA will take over mundane tasks (Chui et al. 2015), thus allowing humans to establish interpersonal communication rather than performing arduous tasks (Wisskirchen et al. 2017). For organizations to remain relevant in the market and compete effectively, investments in RAIA are needed, resulting in major job changes. So investments done at an early stage may be more effective, allowing employees and customers to adjust better to changes and function effectively and efficiently (Webster and Ivanov 2019). A recent study by Raj and Seamans (2019) suggests that the implementation of RAIA requires organizations to be drastically restructured and reshaped, causing changes in employees' skillset requirements and tasks. Employees struggle with the uncertainty related to the implementation of smart technology, AI, robotics, and algorithms (STARA), which could subsequently have a negative impact on the commitment, career satisfaction of employees while increasing their turnover intentions, cynicism, and depression (Brougham and Haar 2018). Perceived job insecurity is not only a consequence of anticipation of job discontinuity but also a projection of jobs becoming extinct (Nam 2019). "Technophobes" display irrational fear toward RAIA, appear to be abnormally anxious, and manifest the fear of unemployment and financial insecurity in comparison with non-technophobes who feel technology generates more job opportunities while banishing inequality (McClure 2018). Kalleberg (2012) suggests that any form of RAIA demands the redesigning of employees' job descriptions and changing focus to performing valueadding tasks; hence, it is seen as a possible facilitator for upskilling jobs leading to better job quality. On the downside, it also standardizes and intensifies work for some employees (Kalleberg 2012). As these technologies gather and disperse enormous amounts of data, privacy becomes an issue, which could potentially affect employees' trust in the organization. Hence, employees' attitudes toward RAIA is affected by concerns regarding their job security, privacy, and wages (Plastino and Purdy 2018). A survey conducted by Deloitte (2017, as cited in Davenport and Ronanki 2018) suggests that challenges faced by executives during the implementation of RAIA initiatives include difficulty in integrating cognitive projects with already existing processes and systems, as well as the high costs of technologies and expertise. However, quality and safety risks associated with RAIA remain undefined but the legal and regulatory implications could be massive (Chui et al. 2015).

\section{RAIA and Job Insecurity}

Studies show that employees across various industries are extremely concerned about their job security due to the implementation of various forms of technologies (Nam 2019). Job insecurity refers to the "sense of powerlessness to maintain desired continuity in a threatened job situation" (Greenhalgh and Rosenblatt 1984, p. 438). It occurs when individuals perceive a potential threat to their job continuity (Davy et al. 1997). In the 1980s, the implementation of RAIA was viewed both negatively, out of fear of the threat posed to job security, and positively, as a result of the greater opportunities it offered (Chao and Kozlowski 1986). RAIA will take over mundane tasks, allowing professionals to cater to clients' needs and devise novel, creative solutions (Plastino and Purdy 2018). A recent study by Davenport and Ronanki (2018) shows that robotic processes may not necessarily lead to job loss and that the main aim of RAIA is not the replacement of managerial employees nor is it the result. Therefore, as technology improves, RAIA projects will cost people their jobs on a smaller scale than expected (Davenport and Ronanki 2018). Knowledge workers, for example, employees in research and development, do not feel threatened by RAIA, as they feel the technology cannot perform creative or emotional tasks (Ili and Lichtenthaler 2017) but may create new jobs. On the other hand, leaders in industries such as retail, insurance, and machinery fear the loss of their jobs with the introduction of RAIA (Agrawal et al. 2017; Davenport and Ronanki 2018; Ivanov 2017). While the elimination of jobs is a major consequence of RAIA implementation (Frank et al. 2017), with the low-skilled workforce becoming unemployed (Hirst 2014), organizations like the Organization for Economic Co-operation and Development (OECD), the World Economic Forum and McKinsey suggest minimum job loss if the creation of new jobs is also considered (Lichtenthaler 2018). 


\section{RAIA and Job Satisfaction}

Job satisfaction is defined as "a pleasurable or positive emotional state resulting from the appraisal of one's job or job experiences" (Locke 1976). Employees' job satisfaction is depicted in their attitude toward their work (Robbins and Coulter 1996). When their responsibilities change and the possibility of layoffs arises, employees begin to question their worth and value, which could potentially have a negative impact on their self-esteem and general life satisfaction (Reinardy 2012). Employees' exposure to technological implementation and greater job complexity using novel technology ameliorates job satisfaction regardless of the job type (Axtell et al. 2002). For example, the implementation of RAIA resulted in pharmaceutical employees appreciating the work design because of the increased contact with the hospital patients, the upskilling of tasks, and the interdisciplinary learning it afforded them (Findlay et al. 2017). Another group perceived this change negatively, as they felt it reduced opportunities for job rotation and teamwork, and limited career opportunities (Findlay et al. 2017). In addition, research shows that gamified job designs ameliorate motivation, satisfaction, and operational performance on the job in manufacturing industries (Liu et al. 2018).

\section{RAIA and Employability}

Employability can be conceptualized as the possession of skills, competencies required to meet the changing needs of employers, customers and, thereby, help individuals to realize aspirations and potential at work (CBI 1999, p. 1). In an age where technology is taking over the jobs of humans, a skilled workforce is imperative to keep abreast of technology. According to the World Economic Forum (2018), the need for emotional and intellectual skills such as complex problem-solving, critical thinking, and coordination will always be high. Soft skills like creativity, empathy, judgment, and the ability to motivate others remain unique to humans (Chui et al. 2015; Lichtenthaler 2018). The development of these skills will have to begin by creating the right foundations, i.e., alterations to the educational system of schools and universities and organizational efforts to train, retrain employees (Webster and Ivanov 2019). Managers' abilities to display "soft skills," such as mentorship and emotional support, will be valued more than just being able to get the job done (Agrawal et al. 2017). Kolbjørnsrud et al. (2016) suggest that "creative thinking" and "experimentation" are required to stay abreast of the changes in the field of RAIA-technology. In addition, acquiring people skills such as social networking, people development, coaching, and collaboration will be imperative for success in the next 5 years, as technology has not yet developed the capability to adapt to the emotional needs of human beings (Kolbjørnsrud et al. 2016). In order to remain employable within the modern workplace, employees would have to be highly adaptable, empathetic, goal-orientated, and focused on the motivational needs of others and leverage technology to achieve their outcomes (Suarta et al. 2017). Chui et al. (2015) suggest redefining and revising job descriptions for $\mathrm{C}$-suite and front-line workers to fully utilize and benefit from the potential of technological advancements around them. This is unlike the implementation of robotic process automation (RPA) in accounting services, which can assist employees with disciplinary issues, but analytical skills, empathy, and creative skills, to a large extent, remain unique to humans (Fernandez and Aman 2018).

\section{Method}

This study was cross-sectional and exploratory in design with the aim of exploring employees' perceptions of RAIA implementation in the workplace and its impact on the psychological aspects of their job. Using purposive sampling, participants were recruited via the researchers' personal, professional network (Kalton 1983) from a population of working adults in different organizations and industries. Setia (2016) defines purposive sampling as a non-probability sampling method based on the researcher's choice and the population that is accessible and available. The research participants are recruited selectively to answer specific research questions (Setia 2016). For this study, a qualitative approach assisted in understanding participants' perceptions, defining the phenomena based on the meanings and variations observed, and generating a theory based on the findings of the interviews (Elliott 1995).

Based on the literature review, the following research questions were formulated for this study:

- What are employees' general perceptions of RAIA?

- What are the perceived risks, benefits associated with implementation of RAIA in the workplace?

- What are employees' perceptions on the impact of RAIA on their current and future job satisfaction, job security, and employability?

\section{Procedure}

Semi-structured interviews were conducted with 21 participants. The interview format varied from face-to-face, telephonic to video call. On average, the interviews lasted about $35 \mathrm{~min}$. The questions revolved primarily around three major psychological aspects of the job, namely job security, job satisfaction, and employability, and interview questions were based on research identified in the literature review (see Appendix A for the interview questions). 
The selection criteria for the sample was either (a) participants were direct or indirect end-users of RAIA, regardless of whether these technologies had already been implemented or had the potential to be implemented in their workplace or (b) if participants are part of the implementation process, they should be an end-user as well. Participant information sheets were shared, and written consent forms were obtained prior to the interview ensuring voluntary participation and conveying they have the freedom to withdraw at any stage of the research study. Participants were assured that confidentiality and anonymity of information would be maintained in the final writeup. Demographic information including date of birth, occupation, designation, years of work experience, and industry was acquired. The views of 21 participants, ranging in age from 25 to 67 years and a gender ratio of four females to seventeen males, were obtained. Three participants had organizational tenure ranging between 20 and 36 years, nine participants had between 9 and 14 years, while the remaining nine participants had between 2 and 8 years of job experience. Participants represented a range of industries, including gaming technology, consultancy firms, psychometrics and recruitment suppliers, manufacturing, human resource consulting, information technology consulting, accounting and finance, retail, management consultancy, and aviation, transportation, and hospitality. They had worked in various parts of the world including the United Arab Emirates, Oman, India, the UK, the USA, and South Africa.

\section{Data Analysis}

The data obtained was analyzed thematically (Braun and Clarke 2006), giving a more attainable and theoretically flexible perspective on the qualitative data obtained, as inductive reasoning was employed to generate themes and sub-themes. Based on the research questions, a large number of codes were extracted and similar, overlapping codes were coalesced. Codes were then placed under broader umbrella themes. Five broad themes and several sub-themes were identified. The five broad themes included (1) understanding from real experience, (2) human touch, (3) outcomes, (4) aftermath of implementation, and (5) conscious efforts (see Table 1 for thematic analysis). Subsequently, the themes were included in the final write-up in order to discuss and elucidate the final themes.

\section{Results}

The value of qualitative research is about gaining the diverse opinions of different participants which could potentially be a representation of the diverse views within a modern workplace. In this study, individuals viewed RAIA implementation in the workplace in several ways, giving interesting perspectives. These perspectives could be considered by organizations when implementing such technologies, as well as by employees if they are the potential end-users; the responses are discussed in the next section (see Table 1).

\section{Discussion}

The findings revealed that there are some alignment and misalignment between the perceptions of the respondents within the current study and what has been found in previous studies. The participants in this study used the terms artificial intelligence (AI) and machine learning (ML) interchangeably, which is conceptually incorrect. AI is capable of finding patterns and predicting the future, whereas ML improves as it performs tasks (Raj and Seamans 2019). Participants indicated that robots cannot make decisions, do not need regular training, unlike humans, and require human contribution, whereas AI learns iteratively and becomes capable of making decisions. In fact, AI that can act of its own volition has not yet been developed (Raj and Seamans 2019). Hence, individuals must expand their technical knowledge and gain conceptual clarity, so they are aware of what they are dealing with. In this study, "human touch" and decision-making capacity were found to be unique to humans and thus irreplaceable. Human involvement will remain vital to the forthcoming fifth industrial revolution (Genpact 2018). This implies that highlevel jobs will not be as affected by technology as low-level jobs, although studies have shown that RAIA will extend to the job content of managerial and executive positions as well (Chui et al. 2015; West 2015). So, this study suggests that individuals should upskill themselves by establishing, maintaining interpersonal relationships with clients and employees to remain employable, which will have an impact on employability or the search for new jobs.

The majority of the respondents had experienced RAIA on a daily basis, be it professionally or personally, which assisted them in personal relations and business dealings (Chui et al. 2015). On the contrary, few respondents have not experienced advanced technology daily. Thus, it is difficult to say whether individuals are always aware of being an end-user of RAIA. Participants appeared to lack knowledge on how RAIA works, how decisions are made, and what happens when they use RAIA; hence, it may be termed a "black box" (Castelvecchi 2016). This study suggests that technology and humans will complement one another as more systems will exploit human and machine intelligence; neither will be able to work without the assistance of the other. Anyone with the right technical expertise is capable of developing a program and running it, but someone who understands the "human context" during implementation will be more sought-after. Thus, the key to remaining employable is keeping oneself abreast of technology (Plastino and Purdy 2018) and molding oneself according 
Table 1 Thematic analysis

S Theme Sub-theme Quotes

no.

1 Understanding from hands-on experience

\section{Perception \\ Decision-making}

Black box

Productivity

Future perception

Hybrid

2 Human touch
No human interaction

Human involvement required

Interpersonal relationship

Person Organization fit

Assessments

Job secure

Job insecurity

Micro-level impact

Indirect impact

Assistance

Work-life balance

Macro-level impact

Algorithms and output

Skillsets possessed

Irreplaceable soft skills “computer system can think for itself...it's more like machine learning."

"computer program and you give a thinking capability, makes its own decision on what to do and its complex stuff."

"robots can do all of that, they cannot get the decision-making power."

"So, it's you and the recording and you do not know what's happening in the back end and you are not getting a response that can be quite tough."

"Just making sure that you are clear on what's happening and not creating an adverse impact."

"If people were able to automate or simulate the human mind...predictions are still very advanced and cannot be effectively replicated with technology; If I get the help of a robot to do the menial part of my job, I would be able to focus my attention on the analytical parts..."

“...it depends on how AI develops. We do not know how it's going to evolve; we do not know that."

"...human process and human intelligence plus machine intelligence needs to go hand in hand"

"...understand the human context"

"I do not believe technology will replace humanity, in fact, humanity will be able to learn more about technology and both will go hand-in-hand. There is no way that technology will replace human beings."

"pre-recording is different...it's taking people out of the loop."

"Many companies sent generic emails...assessments were so inhumane..."

"So, even if it reduces a lot of teamwork, a lot of processes, a lot of people were involved but end of the day operations is run by human beings.... will never take off completely"

"AI cannot manage or copy emotions of people."

"The interpersonal contact between people, not now, will not be able to run by AI or will never happen."

"Computer or AI will not give feedback to individual telling about the strengths and developments. It will list the strengths and developments but elaborating and explaining them...I do not think."

"The privacy element is a risk ... using Facebook or whatever for selection in the future, if they give you access then, you can tap in to pull a personality profile even cognitive profile..."

"So, with every technology enhancement, there are certain jobs, which will disappear, but there are certain new jobs, which will come."

"...creates a skill-depth..."

"I am becoming more efficient to the company"

"...senior level is affected by technology only $20 \%$."

"computers relieve us from systemized boring logic tasks that we do not want to do and open our minds for more creative tasks."

"There is a possibility to tap markets that we have not thought of before."

“...chatbots...it's impractical and does not give the result you require..."

"RAIA reaches out to all employees and takes feedback from the employees... based on their tenure completion... helps to know mood of the employees... gives a list of employees...

HR can reach out and know the reason"

"...outweighed the right to privacy to a more dignified life and I think the quality of life these technologies ensure, really at this stage, outweighs."

"So, there are some good things, but the other risk is if AI ends up in criminal hands, dictators... from my perspective I just do not like AI, it's going to create 'social unrests',

"I honestly did not experience any risk...I did not hear that anybody lost their job because AI, robotics replaced them. I might just not be aware of the risks, but I did not have this in my experience."

4 Milestones

"I've seen increases in jobs, more jobs being created because of these technologies and not necessarily, people who come from educated backgrounds, its people who have learned to code can enter the job market; people will have to be more creative in terms of their efficiency, in terms of their deliverables because if you have something you know which is being automated..."

"...end of the day, of course, humans have to take the decision, AI just supports them take the decisions, wiser decisions." 
Table 1 (continued)

\begin{tabular}{|c|c|c|c|}
\hline $\begin{array}{l}\text { S } \\
\text { no. }\end{array}$ & Theme & Sub-theme & Quotes \\
\hline \multirow{8}{*}{5} & \multirow{8}{*}{ Conscious efforts } & Communication & “.... since they are employees of the organization, we can guide them what to do and what not...' \\
\hline & & $\begin{array}{l}\text { Acceptability and } \\
\text { adaptability }\end{array}$ & $\begin{array}{l}\text { "Being able to master ML or AI applications, } \\
\text { I am more employable and as a result I can experience more security." }\end{array}$ \\
\hline & & $\begin{array}{l}\text { Emotional } \\
\text { dilemma }\end{array}$ & $\begin{array}{l}\text { "...change the picture of work, make it more pleasant and take out the mundane and repetitive } \\
\text { tasks or quickly work on those cognitive elements...in the employees' perspective, } \\
\text { if AI is going wrong then employee does not care about it, if it goes wrong or not." }\end{array}$ \\
\hline & & Degree of impact & "The impact of RAIA has been a lot and I think that in the coming days it will continue to grow' \\
\hline & & $\begin{array}{l}\text { Change in } \\
\text { perspective }\end{array}$ & "I would not say they lost their job, but their job got automated" \\
\hline & & Preparedness & $\begin{array}{l}\text { "I would not say more, the benefits are more appealing, } \\
\text { but you definitely have to manage the risks or otherwise it's just as problematic." }\end{array}$ \\
\hline & & Transparency & $\begin{array}{l}\text { "...when we really know what is happening, everybody in the business knows what is going on, } \\
\text { what technology we are implementing, why we are doing it, and the processes behind it..." }\end{array}$ \\
\hline & & Walk the talk & $\begin{array}{l}\text { "Implementation...should not be undermined... When you are trying to automate something it's } \\
\text { important that it works with what you are trying to achieve as well...needs to be implemented } \\
\text { thoroughly." }\end{array}$ \\
\hline
\end{tabular}

to the technological advancements. A recent study by Petrillo et al. (2018) recommends acquiring new skills to bridge the gap between engineering, computer science, and RAIA. The findings of the current study argue that although the participants were confident in the skillsets they possess, upgradation of their skillsets would build confidence in their employability which would lead to greater job satisfaction and job security.

The present findings lend support to previous studies (Chui et al. 2015; Plastino and Purdy 2018; Raj and Seamans 2019) as they highlight the benefits of RAIA in terms of enhancing employees' ability to do their work as opposed to replacing employees in their work. Participants report better utilization of their time and skills as RAIA eliminates low-value, routine, menial and, strenuous tasks, thus increasing productivity, efficiency, and accuracy, putting employees at their ease. Additionally, although RAIA is believed to assist humans, thereby increasing job satisfaction, it cannot replicate soft skills such as building interpersonal relationships, emotions, creativity, instincts, and decision-making skills, which is consistent with previous research findings (Chui et al. 2015; Lichtenthaler 2018). Humans' emotional needs cannot fully be met by technology as human behavior and emotional needs are highly complex and difficult to understand; however, there is technology available that can respond to basic human emotions and commands (Kolbjørnsrud et al. 2016). For example, although human language skills can be transferred to chatbots, the content and quality of conversations held with humans and with chatbots differ (Hill et al. 2015). The language used by chatbots may be perceived by end-users as impersonal and artificial, as found in the present study.

In addition to organizations making investments at an early stage of RAIA implementation (Webster and Ivanov 2019), this study suggests organizations should communicate effectively about the change, create awareness of it, and encourage employees to accept RAIA with an open mind for a smooth transition through this industrial change. Organizations should develop highly skilled teams, use unbiased algorithms, and ensure proper RAIA implementation to avoid detrimental effects. The study suggests that before implementing RAIA, organizations should become agile, perform thorough research and analysis of the tools, develop a global framework for evaluation, and manage financial investments. Additionally, RAIA can potentially be employed in various departments, increasing efficiency and in turn reducing the workforce. However, there is a need for change in employees' perspectives (Lichtenthaler 2018) thus perceiving RAIA as less threatful and implementing it effectively in various professions. Despite the future being unforeseeable, it has emerged that the participants felt their jobs would be secure in the coming years provided they evolve with the technology. Hence, continuous learning and modifying one's approach to potential technological changes are essential to remain employable. The findings suggest that organizations should use RAIA technologies in their operations in a way that they gain their employees' trust, thus valuing and utilizing human capital. These findings support Raj and Seamans' (2019) study, which indicates that when new technological changes are incorporated into business practices, organizations should involve employees as much as possible to ensure maximum collaboration. Additionally, such advancements should be thought through and not owing to technological trends. This study highlights another perspective, namely, that employees may experience a job satisfaction dilemma. Employees are satisfied with the benefits of RAIA, including rising demand for professionals, work-life balance, unique work, and organizational fairness but less satisfied with its impact on their 
social life, potential misuse of technology, and data theft at the workplace. This implies that not all employees will be satisfied with the implementation of RAIA in the workplace because its impact is subjective depending on employees' job role and seniority level. This study anticipates the emergence of social instability because of higher unemployment and because low-skilled employees will have less possibility of being reskilled or affording access to such advanced technologies. Additionally, when organizations introduce RAIA technology, they should also consider ethical standards, ensure greater transparency in processes, and develop policies in line with the social and cultural dynamics of the country, thus managing the risks well.

Industrial and organizational psychologists could use these findings when managing employee acceptance toward technological change in organizations. This can be done by coaching employees "how" to make themselves employable, advising organizations on "how" to fully utilize its workforce, and have them invest more in retraining employees rather than making them redundant. The findings can also be used as discussion points to figure out the assets and liabilities of the organization. Additionally, the findings recommend that those advancing technologies in the workplace should gain a better understanding of employees', i.e., the end-users, perceptions in order to mitigate the consequences of such advancements. Implementers and employees must be prepared for what is coming; they should be open-minded and flexible in the face of the inevitable fifth industrial revolution.

The mixed sample and the small sample size imply that research findings cannot be generalized to a specific industry or occupation. Although this research found that different nationalities shared similar opinions, more extensive, longitudinal research should be conducted using a larger and more diverse sample. Although the sample was relatively inclusive and diverse in terms of industry, profession, and designation, a subset of low-skilled participants is lacking. Thus, future studies should aim to explore the perceptions of lower level employees.

In conclusion, the study's findings provide a preliminary overview of potential perceptions that may exist toward RAIA and the impact that it may have on employees' job security, job satisfaction, and employability. Due to individual differences, participants perceived technological changes in a similar but not in the same manner. Working of RAIA may be termed as a "black-box" due to lack of transparency in the processes. Employees perceive RAIA as an assistant to human beings in the process of decision-making, performing cumbersome and menial tasks, and saving cost and time thus reducing the workload. Even though there exists a threat to numerable professions, employees feel the urge to accept, adapt, and expand their knowledge to remain employable in the near future. On the contrary, failure of systems and exposure of data is seen as a potential risk of technological advancements.
Varied impact of RAIA on the micro- and macro-level implies that employees may experience a job satisfaction dilemma. Thus, the mixed perceptions of participants suggest that the impact of the implementation of RAIA would vary depending on the industry and seniority level.

Acknowledgements I would like to thank Dr. Marais Bester for his constant guidance from the beginning of the research project to the end and Lucy Bolton for her comments that improved the manuscript. I am also grateful to all the participants who agreed to be a part of this study providing valuable insight and viewpoints. I thank my friends and family for supporting me and constructively criticizing my thoughts and ideas throughout this research study.

\section{Compliance with Ethical Standards}

Ethical approval for the research was granted by the Heriot-Watt University ethics committee. An informed consent was obtained from all participants and the process of this study was conveyed to the participants well in advance ensuring voluntary participation. Confidentiality and anonymity of the participants' personal and organizational information were ensured at all times.

Conflict of Interest The authors declare that they have no conflict of interest.

Open Access This article is licensed under a Creative Commons Attribution 4.0 International License, which permits use, sharing, adaptation, distribution and reproduction in any medium or format, as long as you give appropriate credit to the original author(s) and the source, provide a link to the Creative Commons licence, and indicate if changes were made. The images or other third party material in this article are included in the article's Creative Commons licence, unless indicated otherwise in a credit line to the material. If material is not included in the article's Creative Commons licence and your intended use is not permitted by statutory regulation or exceeds the permitted use, you will need to obtain permission directly from the copyright holder. To view a copy of this licence, visit http://creativecommons.org/licenses/by/4.0/.

\section{References}

Agrawal, A., Gans, J., \& Goldfarb, A. (2017). What to expect from artificial intelligence. MIT Sloan Management Review.

Axtell, C., Wall, T., Stride, C., Pepper, K., Clegg, C., Gardner, P., \& Bolden, R. (2002). Familiarity breeds content: the impact of exposure to change on employee openness and well-being. Journal of Occupational and Organizational Psychology, 75(2), 217-231.

Bowen, H. R. (1966). Report of the national commission on technology, automation, and economic progress (p. 9). Washington: U.S. Government Printing Office.

Braun, V., \& Clarke, V. (2006). Using thematic analysis in psychology. Qualitative Research in Psychology, 3(2), 77-101.

Brougham, D., \& Haar, J. (2018). Smart technology, artificial intelligence, robotics, and algorithms (STARA): employees' perceptions of our future workplace. Journal of Management \& Organization, 24(2), 239-257.

Castelvecchi, D. (2016). Can we open the black box of AI? Nature News, 538(7623), 20-23. https://doi.org/10.1038/538020a.

Chao, G. T., \& Kozlowski, S. W. (1986). Employee perceptions on the implementation of robotic manufacturing technology. Journal of 
Applied Psychology, 71(1), 70-76. https://doi.org/10.1037/00219010.71.1.70.

Chui, M., Manyika, J., \& Miremadi, M. (2015). Four fundamentals of workplace automation. The McKinsey Quarterly, 29(3), 1-9.

Confederation of British Industry (CBI). (1999). Making employability work: An agenda for action. London: CBI.

Davenport, T. H., \& Ronanki, R. (2018). Artificial intelligence for the real world. Harvard Business Review, 96(1), 108-116. https://doi.org/ 10.1016/S0016-3287(03)00029-6.

Davy, J. A., Kinicki, A. J., \& Scheck, C. L. (1997). A test of job security's direct and mediated effects on withdrawal cognitions. Journal of Organizational Behavior: The International Journal of Industrial, Occupational and Organizational Psychology and Behavior, 18(4), 323-349.

Dekker, F., Salomons, A., \& Waal, J. V. D. (2017). Fear of robots at work: the role of economic self-interest. Socio-Economic Review, 15(3), 539-562. https://doi.org/10.1093/ser/mwx005.

Elliott, R. (1995). Therapy process research and clinical practice: practical strategies. In M. Aveline \& D. A. Shapiro (Eds.), Research foundations for psychotherapy practice (pp. 49-72). Chichester: Wiley.

Fast, E., \& Horvitz, E. (2017). Long-term trends in the public perception of artificial intelligence. Proceedings of the Thirty-First AAAI Conference on Artificial Intelligence.

Fernandez, D., \& Aman, A. (2018). Impacts of robotic process automation on global accounting services. Asian Journal of Accounting and Governance, 9, 123-132. https://doi.org/10.17576/AJAG2018-09-11.

Findlay, P., Lindsay, C., McQuarrie, J., Bennie, M., Corcoran, E. D., \& Van Der Meer, R. (2017). Employer choice and job quality: workplace innovation, work redesign, and employee perceptions of job quality in a complex health-care setting. Work and Occupations, 44(1), 113-136. https://doi.org/10.1177/0730888416678038.

Frank, M., Roehrig, P., \& Pring, B. (2017). What to do when machines do everything: how to get ahead in a world of AI, algorithms, bots, and big data. Wiley.

Genpact. (2018). The fifth industrial revolution: When humans and machines combine. Digital Technology Retrieved from https://www. genpact.com/insight/blog/the-fifth-industrial-revolution.

Greenhalgh, L., \& Rosenblatt, Z. (1984). Job insecurity: toward conceptual clarity. Academy of Management Review, 9(3), 438-448.

Hill, J., Ford, W. R., \& Farreras, I. G. (2015). Real conversations with artificial intelligence: a comparison between human-human online conversations and human-chatbot conversations. Computers in Human Behavior, 49, 245-250.

Hirst, T. (2014). Does technological innovation increase unemployment? The World Economic Forum Blog, Agenda Retrieved from https:// agenda.weforum.org/2014/11/does-technological-innovationincrease-unemployment $/$ ?utm_content $=$ bufferccfe $2 \& u t m$ medium $=$ social \&utm_source $=$ facebook.com\&utm_campaign $=$ buffer.

Ili, S., \& Lichtenthaler, U. (2017). Das Ende des traditionellen Bankwesens? Hoffentlich! In R. Smolinski, M. Gerdes, M. Siejca, \& M. C. Bodek (Eds.), Innovationen und Innovationsmanagement in der Finanzbranche (pp. 21-36). Wiesbaden: Springer Gabler.

Ivanov, S. (2017). Robonomics: principles, benefits, challenges, solutions. Yearbook of Varna University of Management, 10, 283-293.

Kalleberg, A. L. (2012). Job quality and precarious work: clarifications, controversies, and challenges. Work and Occupations, 39(4), 427448.

Kalton, G. (1983). Models in the practice of survey sampling. International Statistical Review/Revue Internationale de Statistique, $175-188$.
Kolbjørnsrud, V., Amico, R., \& Thomas, R. J. (2016). The promise of artificial intelligence: Redefining management in the workforce of the future. Accenture Institute for High Performance Business. Retrieved from https://www.accenture.com/_acnmedia/PDF-19/ AI in Management_Report. PDF.

Lichtenthaler, U. (2018). Substitute or synthesis: the interplay between human and artificial intelligence. Research-Technology Management, 61(5), 12-14. https://doi.org/10.1080/08956308. 2018.1495962.

Liu, M., Huang, Y., \& Zhang, D. (2018). Gamification's impact on manufacturing: enhancing job motivation, satisfaction and operational performance with smartphone-based gamified job design. Human Factors and Ergonomics in Manufacturing \& Service Industries, 28(1), 38-51.

Locke, E. A. (1976). The nature and causes of job satisfaction. Handbook of industrial and organizational psychology (pp. 1297-1349).

McClure, P. K. (2018). You're fired, says the robot: the rise of automation in the workplace, technophobes, and fears of unemployment. Social Science Computer Review, 36(2), 139-156. https://doi.org/10.1177/ 0894439317698637.

Nam, T. (2019). Technology usage expected job sustainability, and perceived job insecurity. Technological Forecasting and Social Change, 138, 155-165.

Petrillo, A., Felice, F. D., Cioffi, R., \& Zomparelli, F. (2018). Fourth industrial revolution: current practices, challenges, and opportunities. Digital Transformation in Smart Manufacturing, 1-20.

Plastino, E., \& Purdy, M. (2018). Game changing value from artificial intelligence: eight strategies. Strategy \& Leadership, 46(1), 16-22.

Raj, M., \& Seamans, R. (2019). Primer on artificial intelligence and robotics. Journal of Organization Design, 8(1), 11.

Reinardy, S. (2012). Job security, satisfaction influence work commitment. Newspaper Research Journal, 33(1), 54-70.

Robbins, S. P., \& Coulter, M. (1996). Management. Upper Saddle River: Prentice-Hall.

Setia, M. S. (2016). Methodology series module 5: sampling strategies. Indian Journal of Dermatology, 61(5), 505-509. https://doi.org/10. 4103/0019-5154.190118.

Suarta, I. M., Suwintana, I. K., Sudhana, I. F. P., \& Hariyanti, N. K. D. (2017). Employability skills required by the 21st century workplace: a literature review of labor market demand. In International Conference on Technology and Vocational Teachers (ICTVT 2017). Atlantis Press.

Webster, C., \& Ivanov, S. H. (2019). Robotics, artificial intelligence, and the evolving nature of work. In B. George \& J. Paul (Eds.), Business transformation in data driven societies. Palgrave-MacMillan.

West, D. M. (2015). What happens if robots take the jobs? The impact of emerging technologies on employment and public policy. Washington, DC: Centre for Technology Innovation at Brookings.

Wisskirchen, G., Biacabe, B. T., Bormann, U., Muntz, A., Niehaus, G., Soler, G. J., \& von Brauchitsch, B. (2017). Artificial intelligence and robotics and their impact on the workplace. IBA Global Employment Institute, 2012-2017.

World Economic Forum. (2018). The future of jobs report 2018. Geneva: World Economic Forum Retrieved from http://www3.weforum.org/ docs/WEF_Future_of_Jobs_2018.pdf.

Publisher's Note Springer Nature remains neutral with regard to jurisdictional claims in published maps and institutional affiliations. 